\title{
IMIGRAÇÃO AMERICANA NA PROVÍNCIA DE SÃO PEDRO DO RIO GIRANDE DO SUL NO ANO DE 1867
}

Hilda Agnes Hübner Flores

No acervo do Arquivo Histórico do Rio Grande do Sul encontra-se o CÓDICE C 257, que registra a correspondência expedida nos anos de 1864-1870 pelo Diretor Geral da Colonização aos Agentes Imtérpretes da Colonização e aos Diretores das diferentes colônias que então se formavam, dentro da política imigratória que a Província adotava. Refere-se, na maior parte, à colınização européia, mormente imigrantes de fala alemã que se localizaram em Santa Cruz, Monte Alverne, Santo Ângelo, Nova Petrópolis, São Lourenço e também à colônia milittar de Caseros. Mas no ano de 1867 há correspondência relacionada à chegada de imigranttes norte-americanos.

Segundo Kliemann eram americanos do Sul, que abandonaram sua pátria após o término da Guerra de Secessão, pois “Em 1865 [...] o Sul é vencido pelo Norte e, a partir de 1866, a política doss EUA força os Sulistas à emigração, um vez que o predomínio ianque se fez cada wez mais atuante". 1

De acordo com o Relattório Anual do Ministro Manuel Pinto de Souza Dantas, procediam do Mississipi, Texals, Carolina do Sul, Arkansas, Luiziânia, Maine e ainda Canadá, e localizaram-se nas Províncias de Pará, Alagoas, Espírito Santo, Paraná, São Paulo, Santa Catarina e Rio Grande: do Sul. ${ }^{2}$

O Governo Brasileiro, demtro do que Manfroi chama de "colonização propaganda", destinada a mostrar no exterior "o caráter liberal e generoso da legislação brasileira", 3 esteve atento aos interesses que desde os primeiros meses de 1865 manifestaram "os habitantes de alguns estados do sul da União Americana para transferir sua morada para o Brasil". Destinou-lhes terras deevolutas ou de propriedades particulares, mandando, pela circular de 14/5/1867, demarcar "primeiramente as terras de mais facil acesso, quer por terra, quer por mar. .."4

Dum total de 77 e mejia léguas quadradas de terra que o Império destinou à imigração americana, nove, ou seja, 91 braças quadradas situavam-se na Província de São Pedro do Rio Grande do Sul. ${ }^{5}$

O CÓDICE C 257 registtra a correspondência sobre imigração norte-americana ao longo do ano de 1867 e iní́cio de 1868. Num total de 43 ofícios, datados entre $18 / 1 / 1867$ e 23/3/1868, iniciia com bastante otimismo, que se esvai até culminar em silêncio absoluto a partir de miarço de 1868 , quando registra a emigração de um colono para os Estados Unidos. 


\section{A Chegada}

Em 18/1/1867 o Diretor Geral da Colonização comunica ao Agente Intérprete que chegaram "a cidade de Rio Grande 39 Norte-Americanos [. . . ] para se estabelecerem onde desejarem," achando-se o Diretor Geral da Colonização autorizado

[...] por Aviso do Ministerio da Agricultura, Commercio e obras publicas de 5 do corrente a mandar medir lotes de terras devolutas contiguas a qualquer das colonias que parecer mais conveniente e distribuil-as pelos emigrantes a titulo de venda a prasos, na rasão de um real a braça quadrada e mediante reembolso dentro de 5 annos a contar do $2^{\underline{0}}$ do estabelecimento.

Cabia ao Agente Intérprete tomar as providências necessárias à recepção e alojamento dos imigrantes.

Através de 9 ofícios, datados entre 18/1 e 23/4/1867, há referência à vinda de sucessivas levas de americanos, a maioria pelo porto de Rio Grande, e alguns via Santa Catarina. Estes ofícios eram acompanhados de relação nominal dos recém-chegados, que não conseguimos localizar. ${ }^{7}$

A dinâmica da correspondência deixa entrever a chegada de algumas centenas de pessoas ao Rio Grande do Sul; o Relatório do Ministro da Agricultura dá como dado oficial 259. Foi a Província que mais americanos recebeu, seguida de São Paulo (206), Santa Catarina (206), Pará (61), Paraná (13), Pernambuco, Minas e Bahia, todas com menos de uma dezena, num total de 761 pessoas. $^{8}$

\section{Transporte, Alojamento e Alimentação}

A correspondência do CÓDICE faz referência a diversos vapores - Gerente, Santa Cruz - que' trouxeram os americanos do Rio de Janeiro até o porto de Rio Grande, onde faziam baldeação e parcelamento de levas, para embarque até Porto Alegre em vapores menores como Fluminense, Proteção, vapores da Companhia Jacuhy:

Com os seus dous officios de 21 do corrente recebi a relação dos emigrantes americanos, que ultimamente vierão da Côrte no vapor Santa Cruz, sendo dos que chegarão a esta capital no vapor Proteção e dos que ficarão no Rio Grande, aquelles em número de 29 e estes em numero de 24, faltando para o completo de 55, que embarcarão na Côrte, dous; dos quaes um cahio ao mar e desapareceu [...] e o outro por doença ficou em Santa Catarina. Para se lhe mandar abonar a quantia necessaria para occorrer as despesas com os emigrantes chegados a esta capital [...] é preciso que $\mathrm{Vm}^{\mathrm{ce}}$. me apresente o orçamento detalhado do que tiver de se despender com elles até o lugar de destino. ${ }^{9}$

De Porto Alegre os imigrantes deviam seguir viagem até as colônias de Santo Ângelo ou Nova Petrópolis. O transporte era inteiramente por conta do Governo brasileiro:

Achando-se actualmente occupado o quartel dos Guaranys pelas praças de bateria de voluntarios allemães e não podendo por emquanto servir de alojamento aos 220 colonos americanos que estão em viagem para esta provincia e hão de chegar aqui brevemente, autorizo a $\mathrm{Vm}^{\mathrm{ce}}$. a alugar uma casa ou armazem onde elles posão ser recolhidos emquanto não seguirem para as colonias provinciaes ou não tomarem outra qualquer direção. ${ }^{10}$ 


\section{Em Rio Grande foi autorizado o}

Administrador da mesa de rendas dessa cidade a alugar [. . .] uma casa ou armazem para servir-lhes de alojamento. ${ }^{11}$

Quando chegavam levas menores a Porto Alegre, eram por vezes acomodados em hospedarias ou prédios alugados. ${ }^{2}$ Em Nova Petrópolis foi autorizada a construção de um barracão e utilizadas diversas barracas, para acomodar os colonos norte-americanos que para lá se dirigiram.

Relativos à alimentação, há também diversos ofícios com ordem de pagamento para fornecedores de gêneros, entre eles Victor Telles e Frederico Köhnke em Rio Grande, e a João Weiss em Porto Alegre:

[...]nesta data expeço ordem à Thesouraria de Fasenda para mandar pagar a João Weiss a conta, que accompanhou o seo officio de hontem datado, de viveres que forão fornecidos aos colonos Norte-americanos que aqui chegarão a 16 de Outubro deste anno, vindos da Provincia de S. Catharina. ${ }^{13}$

Em 13/3/1868 há ordem de pagamento, pelo fornecimento de comedorias, para Américo Pinheiro da Cunha. ${ }^{14}$

O Agente Intérprete de Rio Grande foi autorizado "[. . . a comprar os utensilhos precisos como sejão panellas lampiões pipa para agua apresentando depois a conta respetiva para ser paga"; o fornecimento de víveres devia ser feito "pela tabela em vigor [. . .] a rasão de 440 reis diarios por pessoa". ${ }^{15}$

\section{Subsídio}

A imigração americana foi financiada pelo Governo Imperial. Devia o Agente Intérprete

[...]remeter a conta da despesa que fes jus com dous colonos Norte-americanos na importancia de $19 \$ 000$, para ser mandar pagar pela Thesouraria da Fasenda, visto que estas despesas não correm por conta dos coffres provinciaes procedendo de igual modo com outras que fiser com outros que venhão por conta do Governo Geral com destino ás colonias da Provincia. ${ }^{16}$

Para se estabelecerem em Santo Ângelo foi estabelecida a quantia de 1:000\$000 réis, conforme ordem de pagamento, pela Tesouraria da Fazenda. ${ }^{17}$ A correspondência do CÓDICE C 257 não deixa entrever como foi gasta esta verba, mas no mês seguinte foi aberto

[...] mais um crédito de 5:150\$000 reis para continuação das despesas a faser com o estabelecimento dos colonos Norte-americanos vindos para esta provincia. ${ }^{18}$

Este é o maior crédito a que o CÓDICE faz referência. No mês subseqüente mais 1:933\$000 réis foram destinados pela Tesouraria da Fazenda para “os emigrantes americanos chegados a esta capital". ${ }^{19}$ 
Aos cofres imperiais cabia também a manutenção dos imigrantes, conforme atestam diversas ordens de pagamento de fornecimento de gêneros alimentícios, assim como o pagamento de auxílio pecuniário que era pago inicialmente aos colonos:

A conta que accompanhou seu officio [...] foi remettida á Thesouraria da Fasenda para entregar a $\mathrm{Vm}^{\mathrm{ce}}$. a quántia de $150 \$ 040$, em que importão os subsidios dos colonos Norte-Americanos - estabelecidos em Nova Petropolis. ${ }^{20}$

Ao Governo provincial cabia, entre outros, a conservação dos prédios que serviam de hospedaria:

[... .]determino ao Diretor Geral dos Negocios da Fasenda Provincial que manda faser por arrematação, os concertos mais urgentes de que precisa o Quartel dos Guaranys para servir de alojamento aos colonos, emquanto se conservão nesta capital. ${ }^{21}$

\section{O Decreto N. ${ }^{0} 3784$, de 19 de Janeiro de 1867}

Se, como vimos anteriormente, o Relatório do Ministro Souza Dantas deixa claro o grande interesse do governo brasileiro pela vinda de norte-americanos para a nossa agricultura, a correspondência do CÓDICE C 257, por outro lado, deixa entrever que este imigrante vinha com maiores pretensões que o europeu em geral. Ao contrário deste, podia escolher suas terras:

Tendo chegado 39 emigrantes Norte-americanos [...] para se estabelecerem onde desejarem. . 22

Nem todos escolheram a colônia, e os que o fizeram impuseram exigências que desconhecemos no imigrante europeu:

[...] dos 28 colonos Norte-americanos, que atualmente chegarão a esta capital só restão 18 , que preferem estabelecer-se nas colonias provinciaes exigindo, porem, que thes sejão dados lotes medidos e demarcados, com derrubadas feitas e cercas provisorias para sua primeira acomodação, subsidios por seis meses, instrumentos agrarios e sementes; tenho a significar a $\mathrm{Vm}^{\mathrm{ce}}$ para que faça constar aos referidos emigrantes que esta presidencia só lhes pode conceder as vantagens constantes no Aviso do Ministerio de Negocios de Agricultura Commercio e obras publicas de 24 de Novembro publicado no Diario Official de 21 de Dezembro de 1866, que the remetto.

No mesmo dia aditava:

[...] aos Diretores das colonias que forem escolhidas pelos emigrantes norte-americanos, que tratem quanto antes de medir lotes coloniaes, assim como de mandar faser derrubadas e casas provisorias. . ${ }^{23}$

Afora os barracões de alojamento existentes nas colônias e as derrubadas feitas pelos próprios colonos, no sistema de trabalho quinzenal remunerado, o CÓDICE não dá notícias da concretização, pelo Governo, de medidas como "derrubadas e casas provisorias".

Três dias após o ofício anterior, o Diretor Geral redigia: 
[...] em addidamento ao meu officio de 23 do corrente, determino a $\mathrm{Vm}^{\text {ce }}$. que [...] faça observar tanto quanto possivel as disposições mandado executar pelo decreto de 19 de Janeiro do corrente anno o qual foi publicado no Diario Official n. ${ }^{0} 20$ de 21 do citado mes. $^{24}$

Tratava-se do Decreto n. ${ }^{\mathrm{O}} 3784$, que passou a reger a colonização americana a partir de então. O ministro Souza Dantas, seu autor, explica que havia, ao longo do Império, inúmeras ordens e determinações, às vezes contraditórias, nascidas em prol da imigração e que por isto reuniu

[...] em um regulamento comum a todos os estabelecimentos coloniaes pretencentes ao estado, existentes ou futuros, as disposições esparsas mais aproveitaveis, ás quaes addicionou outras. . . ${ }^{25}$

\section{No CÓDICE C 257 encontramos alguns artigos deste Regulamento:}

[...] abono de comedorias para os primeiros 10 dias de estada na colonia e a quinze dias de salário por mes ou noventa dias no semestre, isto quando houver trabalho na Colonia e os colonos não tenhão meios sufficientes e queirão prestar-se ao serviço $[\ldots]^{26}$

O abono de gratificação de $20 \$ 000$ reis, do art. do Decreto 3784 de 19 de Janeiro de 1867 , deve ser feito não só aos colonos de que trata o dito parecer,como aos colonos chefes de familia maiores de 50 anos, que a ele tenhão direito. ${ }^{27}$

Era concedido somente a colonos do sexo masculino.

Os colonos americanos recebiam $10 \$ 000$ réis diários, por 10 dias, desde que efetivamente se estabelecessem em colônias. Por isso era recomendado:

Senso de economia em conceder abono de $10 \$ 000$ reis ao imigrante que chegado a Rio Grande, não se destinasse ás colonias. ${ }^{28}$

\section{Destino}

O objetivo do Governo era a colonização, embora já admitia desde o início outra hipótese, mandava providenciar

[...] uma casa ou armazem onde elles possão ser recolhidos emquanto não seguirem para as colonias provinciaes ou não tomarem outra qualquer direção. ${ }^{29}$

Duas semanas após a correspondência mostrava que efetivamente nem todos os imigrantes que chegaram se encaminharam à agricultura:

[...] dos 28 colonos Norte-americanos, que ultimamente chegarão a esta capital só restam 18 que preferem estabelecer-se nas colonias provinciaes. ${ }^{30}$

Qual o destino dos restantes 10 ?

Em fins de fevereiro comunicava o Diretor Geral que ainda não estava

[...] designado o local onde se deve fundar colonias geraes, devendo conforme as ordens do Governo Imperial estabelecer-se os emigrantes Norte-americanos que já tem vindo para a Provincia em terras devolutas contiguas as colonias provinciaes. . ${ }^{31}$ 

ordem

No dia seguinte o mesmo Diretor comunicava ao Agente Intérprete que expediu

[...] á Thesouraria da Fasenda [...] para que the mande entregar a quantia de 1:000 $\$ 000$ reis para occorrer as despesas a faser-se como os emigrantes que vão estabelecer-se em S. Ângelo ${ }_{i}^{32}$

Não há informações sobre as condições em que Santo Ângelo foi ocupada; apenas um lacônico ofício de 28/6/1867 registra o abandono da colônia por 5 americanos, que se dirigiram em direção ao Uruguai. Sabe-şe que nenhum americano permaneceu nesta colônia, permanentemente.

\section{Nova Petrópolis}

Maiores informações há sobre Nova Petrópolis, onde realmente os imigrantes americanos se fixaram por algum tempo. Em 27/3/1867 foi fretado por $300 \$ 000$ reis um dos vapores da Companhia Jacuhy

[...] para transportar até o porto das Larangeiras os colonos Norte-Americanos que estão aboletados em uma das Ilhas fronteiras para que seguissem d'ali a Colonia de Nova-Petropolis, onde se vão estabelecer. ${ }^{33}$

De acordo com o Dec. 3784, o Governo brasileiro utilizou o imigrante para abrir estradas. O colono sem recurso trabalhava 15 dias por mês, ou 90 consecutivos, sob remuneração. Esta podia ser descontada até $50 \%$, para pagamento de suas dívidas, contraídas com o governo na aquisição de lotes coloniais.

Tal medida tinha a dupla vantagem de alargar as estradas do vasto Império, notadamente aquelas que diretamente serviam à colocação dos produtos coloniais, e auxiliava economicamente o colono, enquanto este não colhesse, para seu sustento, os frutos da terra que cultivava.

Os dois ofícios abaixo, que transcrevemos na íntegra, mostram que os americanos em Nova Petrópolis foram também utilizados nesse tipo de trabalho, com o qual, no entanto, não se enquadraram, a julgar por suas reivindicações, e pela decisão oficial de desviá-los do trabalho de abertura de estradas, para outro menos especializado, como o de derrubada de mato:

\section{Ao Agente Interprete da Colonisação}

Inteirado pelo seu officio, de hoje, ter vindo apresentar-se-lhe, por parte dos emigrantes Norte-americanos, que seguirão para a colonia de Nova Petropolis, uma comissão, com o fim de reclamar augmento de salario, por não ser-lhes possivel trabalhar e sustentar-se diariamente com 640 reis, pelo que tomou $\mathrm{Vm}^{\text {ce }}$. a deliberação de elevar o mesmo salario para 1000 por dia; tenho a declarar-lhe que aprovo esta sua deliberação visto que ainda assim é menor este salario do que qualquer que se paga aos trabalhadores nas colonias. Ao Diretor daquella Collonia pode $\mathrm{Vm}^{\text {ce }}$. declarar que empregue na abertura da estrada que da linha Pirajá se dirige a Povoação de N. Petropolis, os emigrantes norte-americanos, se nesse serviço poder com vantagem ser utilisado o seu trabalho; no caso contrario, porem, continuará o mesmo serviço a ser feito pelos colonos allemães; sendo então aquelles 
empregados em trabalhos de derrubadas, e outros, que não requeirão pratica especial. Correndo a despesa com a dita estrada por conta dos cofres provinciaes, se taes emigrantes forem empregados nos respectivos trabalhos, os salarios que vencerem correrão tambem por conta d'aquelles cofres. Aos mencionados emigrantes poderá o referido Diteror dar trabalho, se elles o pedirem, por mais alguns dias além dos 15 de cada mes que se achão fixados para seu sustento. Fica tambem aprovada a deliberação que $\mathrm{Vm}^{\mathrm{ce}}$. tomou e de que $\mathrm{Vm}^{\mathrm{ce}}$. me da parte no final do citado officio, de mandar dar passagens no vapor de S. Leopoldo, e fornecer comedorias por um dia que estiverão nesta capital, aos tres emigrantes que vierão commicionados reclamão aquelle augmento de salario, visto acharem-se desprovidos de meios para faserem esta despesa a sua custa. Cumpre porem, observar que mandando esta Presidencia trabalhar aos citados emigrantes por conta dos coffres provinciaes essencialmente para garantir-lhes o seu sustento, é de mister que, logo que haja serviços cujas despesas devam correr pelos coffres geraes, elles passem a empregar-se nestes exclusivamente. ${ }^{34}$

Tendo em consideração as ponderações que $\mathrm{Vm}^{\mathrm{ce}}$. fas em officio de 23 do corrente mes relativamente ás despesas feitas pelo Diretor da Colonia Nova Petropolis com os salarios dos colonos Norte-Americanos, que trabalhão na abertura das estradas que da linha Pirajá se dirige a povoação da referida colonia e da linha Christina ao porto de linha Felis; nesta data expeço ordem á Diretoria geral dos Negocios da Fasenda provincial para que mande pagar a quantia de $918 \$ 660$ reis em que importam as ferias do mes de Abril remettidas com o citado officio. Logo que o mencionado Diretor regressar à colonia, deve, como se propõe, despedir aquelles colonos do serviço em que estão permitindo-lhes trabalhar onde e em que quiserem, os quaes receberão somente, como subsidio diario, os adultos quatrocentos e quarenta reis e os menores duzentos e vinte reis. ${ }^{35}$

Enquanto o colono europeu, de uma maneira geral, trabalhava com afinco na sua terra, para compensar os 15 dias que trabalhava assalariado, o americano, inconformado, reivindicava direitos e vantagens. Os colonos americanos de Nova Petrópolis "[. . .] vierão a esta capital reclamar o pagamento dos salarios vencidos em Abril e Maio findos", tendo

[. . . ] regressado a Nova Petropolis os 14 dos 16 que vierão a esta Capital, depois de lhes fornecer varias peças de vestuario cuja despesa bem como a de transporte e sustento nesta cidade serão dedusidas dos salarios que teem a receber. ${ }^{36}$

\section{Evasão e Abandono}

Diversos ofícios acusam evasões de norte-americanos que decidiram não se encaminharem às colônias. Para isso usavam diversas artimanhas, como o não comparecimento ao local de embarque:

[...] fiquei inteirado do procedimento reprehensivel que tem tido diversos colonos Norte-americanos chegados a Provincia, já recebendo hospedagem e mantimentos na cidade de Rio Grande declarando-se dispostos a seguir para as colonias da Provincia e depois ausentando-se na ocasião do embarque, já recebendo donativos em dinheiro e terras nessas colonias, e depois fugindo delas. . ${ }^{37}$

Isto levou o Governo brasileiro a tomar medidas de precaução:

[...] donativo gratuito que deve somente fornecer aos que thes parecerem dispostos a permanecer nas colonias. ${ }^{38}$ 
Havia também o artifício da troca de identidade para escapar à responsabilidade assumida, o que valeu Aviso circular reservado do Ministro da Agricultura:

[...] convem evitar todos os motivos de duvidas quanto a identidade dos individuos que emigram para o Brasil, procedentes dos Estados Unidos, o que poderá ser origem de complicações e prejuisos futuros; por isso $\mathrm{Vm}^{\mathrm{ce}}$. faça submeter a mais rigorosa investigação qualquer americáno que, chegando a esta Provincia com um nome, apresente-se depois com outro. ${ }^{39}$

Na realidade, e apesar dos cuidados do Governo, a colonização americana não fixou raízes no Rio Grande do Sul. Pe. Schmitz em seu estudo sobre Nova Petrópolis dá como etnias que entraram em sua formação: pomeranos, alemães, saxões, boêmios, luso-brasileiros e italianos. ${ }^{40}$

Em 1870 já nenhum colono norte-americano encontrava-se em Nova Petrópolis, de acordo com Helga Piccolo, que registra, naquele ano, a existência de 1.182 habitantes, assim distribuídos: 639 alemães, 495 brasileiros, 27 holandeses e 21 franceses, quadro que se configura estável nas estatísticas subseqüentes, até $1874 .^{41}$

Koseritz em seu Relatório do $1 .^{\circ}$ semestre de 1867 considera os 157 imigrantes até então chegados à Província, em vista das graves e inúmeras alterações que deram ao Governo, gente que prestou "um eminente serviço á polícia americana, mudando seus domicilios para o Brasil". Havia entre eles apenas 13 norte-americanos natos; os demais eram irlandeses, franceses, ingleses, escoceses e alguns alemães. ${ }^{42}$

Assim, esta imigração que foi esperada como a "aurora de uma nova era de prosperidade e progresso" apresentou-se na realidade como um mau negócio para o Governo brasileiro, que gastou com ela 11 contos de reis, sem nenhum proveito para o futuro. 43

Faculdade dos Meios de Comunicação Social Pontifícia Universidade Católica

Porto Alegre, Brasil 


\section{NOTAS}

1 Luiza Kliemann, "Notas para um estudo da imigração norte-americana e suas influências na cultura brasileira (1823-1889)", Estudos Ibero-americanos, vol.II, n. ${ }^{0} 1$, julho de 1976, pág. 41.

${ }^{2}$ Relatório do Ministro de Agricultura, Comércio e Obras Públicas (Rio de Janeiro, Tipografia Perseverança, 1867), pág.60-5.

${ }^{3}$ Olívio Manfroi, A colonização italiana no Rio Grande do Sul (Porto Alegre: IEL/DAC/SEC, 1975), pág. 84-7.

${ }^{4}$ Relatório do Ministro da Agricultura, Comércio e Obras Públicas, op. cit., pág. 66.

5 Idem, ibidem, pág. 61.

${ }^{6}$ Arquivo Histórico do Rio Grande do Sul: CÓDICE C 257, Ofício do Diretor Geral da Colonização, Antonio Augusto Pereira de Cunha, ao Agente Intérprete da Colonização em P. Alegre, Carlos von Koseritz, em 18/1/1867, pág. 57V. Todos os ofícios subseqüentes que se referem à imigråção norte-americana - 43 no total - são expedidos por Francisco Ignacio Marcondes Homem de Melo, Diretor Geral da Colonização, que viria mais tarde ocupar a presidência da Província. O Agente Intérprete permaneceu o mesmo.

${ }^{7}$ Ao longo da correspondência arrolam-se os nomes de Jacob Doems, Clodine Woger, Jacob Lubcher, Henrique Rampt, João Wunsch, H. Landon, Leopoldo Busch (of. de 29/1/1867, pág. 58); E.A. Benjamin (of. de 23/2/1867, pág. 60V); J.P. Gesffroy, Henrique Wilsen (of. de 16/3/1867, pág. 63V); George Lund Smith, Henry Barquevith, Thomas Weid, Brijan Mac Swency, Ruben G. Thomas (of. de 28/6/1867, pág. 72); James I. Rily, John Whit (of. de 3/6/1867, pág. 73V); Charles Aguiar, Francis Casothan, Willian B. Castelin (of. de 18/11/1867, pág. 80V); e Jean François Rousseau (of. de 24/3/1867, pág. 89). No mesmo Arquivo Histórico existe, na Pasta "Diversos" que trata da colonização, uma lista de 24 norte-americanos chegados à Província do Rio Grande do Sul a 10/6/1867 no vapor Guaporé. Os 6 nomes grifados correspondem aos que chegaram a Porto Alegre dois dias após, com destino às colônias provinciais: Michel Kelly, Bridget Kelly, - mulher, Mary Kelly - filha, Coundy Gallagher, Anna Gallager - mulher, Eduardo O'Donnel, Daniel Ferry, Eduardo Cunin, Anton Call, Pedro Scherkey, John Donly, Patrick Cowray, Eduardo Fully, James Harkins, Thomas Call, Johann Buttlinder, Victor Julien, Catarina Julien - mulher, Denis Graire, Blanche Graire - mulher, Leon Graire - filho, George Wolff, Carolina Wolff - mulher, James Ferry.

${ }^{8}$ Relatório do Ministro de Agricultura, Comércio e Obras Públicas, op. cit., pág. 67.

9 Arquivo Histórico do Rio Grande do Sul: CÓDICE C 257, op. cit., of. de 23/4/1867, pág. 67.

${ }^{10}$ Idem, ibidem, of. de 9/2/1867, pág. 59.

11 Idem, ibidem, of. de 25/2/1867, pág. 61 .

12 Idem, ibidem, of. de 16/3/1863, pág. 63V.

13 Idem, ibidem, of. de 24/12/1867, págs. $83 \mathrm{~V}$ e 84 .

14 Idem, ibidem, of. de 13/3/1867, pág. 90V.

15 Idem, ibidem, of. de 28/3/1867, págs. 64 e 64V.

16 Idem, ibidem, of. de 23/3/1867, pág. 64V.

${ }^{17}$ Idem, ibidem, of. de 27/2/1868, pág. 61V. 
18 Idem, ibidem, of. de 30/3/1867, pág. 64V.

19 Idem, ibidem, of. de 25/4/1867, pág. $67 \mathrm{~V}$.

20 Idem, ibidem, of. de 10/10/1867, pág. 79V.

21 Idem, ibidem, of. de 2/5/1867, pág. 68 .

22 Idem, ibidem, of. de 18/1/1867, pág. 57V.

23 Idem, ibidem, of. de $23 / 2 / 1867$, págs. 60 e $60 \mathrm{~V}$.

24 Idem, ibidem, of. de 26/6/1867, pág. 61V.

25 Relatório do Ministro da Agricultura, Comércio e Obras Públicas, op. cit., pág. 81.

26 Arquivo Histórico do Rio Grande do Sul: CŌDICE C 257, op. cit., of. de 12/9/1868, pág. $106 \mathrm{~V}$.

27 Idem, ibidem, of. de 4/11/1868, pág. 110.

28 Idem, ibidem, of. de 25/2/1867, pág. 61.

29 Idem, ibidem, of. de 9/2/1867, pág. 59.

30 Idem, ibidem, of. de 23/2/1867, pág. 60 .

31 Idem, ibidem, of. de 26/2/1867, pág. $61 \mathrm{~V}$.

32 Idem, ibidem, of. de 27/2/1867, pág. $61 \mathrm{~V}$.

33 Idem, ibidem, of. de 23/7/1867, pág. 64.

34

Idem, ibidem, of. de 12/4/1867, pág. 66 .

35 Idem, ibidem, of. de 24/5/1867, págṣ. $69 \mathrm{~V}$ e 70 .

36 Idem, ibidem, of. de 6/61867 e 7/6/1867, pág. 73.

37 Idem, ibidem, of. de 29/6/1867, pág. 74V.

38 Idem, ibidem, of. de 18/10/1867, pág. 80.

${ }^{39}$ Idem, ibidem, of. de 6/4/1867, pág. 65 .

${ }^{40}$ P. e. Arsênio José Schmitz, Uma nova imagem para Nova Petrópolis (Roma: Tip. della Pontificia Università Gregoriana, 1975), págs. 32 e 33.

${ }^{41}$ Helga Iracema Piccolo, “A colonização alemã em Nova Petrópolis", Rev. do Instituto de Filosofia e Ciências Humanas, Porto Alegre, UFRGS, 1974, pág. 337-41.

42 Relatório da Administração Central das Colônias da Prov. de São Pedro do Rio Grande do Sul apresentado a Francisco Ignacio Marcondes Homem de Mello pelo Agente Intérprete da Colonização Carlos von Koseritz, em 15/7/1867, pág. 58.

${ }^{43}$ Idem, ibidem, pág. $56 \mathrm{~V}$. 